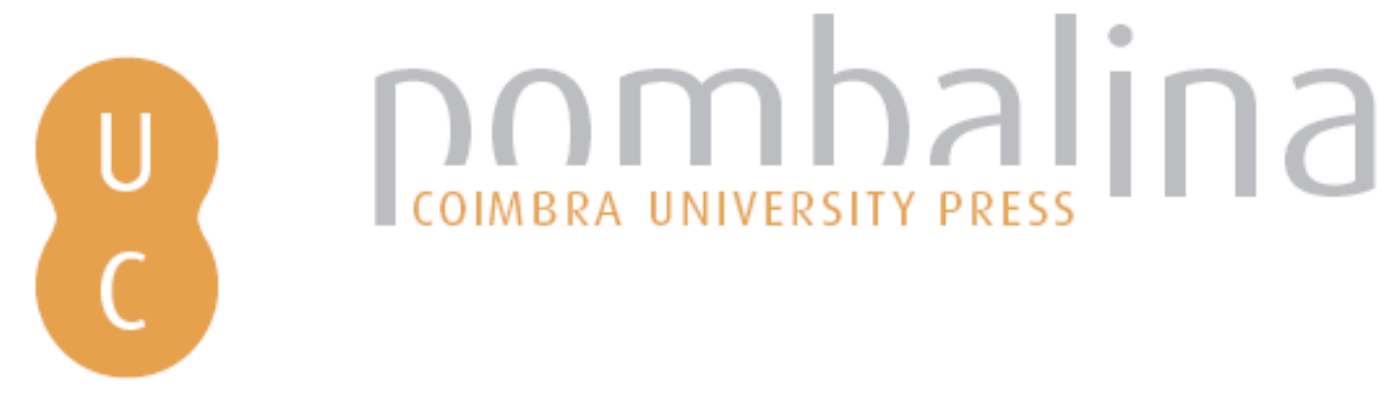

\title{
Estados Unidos e Europa: entre parceria e isolacionismo
}
Autor(es):
Rocha, Miguel de Oliveira Estanqueiro
Publicado por: Imprensa da Universidade de Coimbra
URL persistente:
URI:http://hdl.handle.net/10316.2/47297
DOI:
DOI:https://doi.org/10.14195/978-989-26-1849-4_6
Accessed : $\quad$ 26-Apr-2023 07:54:55

A navegação consulta e descarregamento dos títulos inseridos nas Bibliotecas Digitais UC Digitalis, UC Pombalina e UC Impactum, pressupõem a aceitação plena e sem reservas dos Termos e Condições de Uso destas Bibliotecas Digitais, disponíveis em https://digitalis.uc.pt/pt-pt/termos.

Conforme exposto nos referidos Termos e Condições de Uso, o descarregamento de títulos de acesso restrito requer uma licença válida de autorização devendo o utilizador aceder ao(s) documento(s) a partir de um endereço de IP da instituição detentora da supramencionada licença.

Ao utilizador é apenas permitido o descarregamento para uso pessoal, pelo que o emprego do(s) título(s) descarregado(s) para outro fim, designadamente comercial, carece de autorização do respetivo autor ou editor da obra.

Na medida em que todas as obras da UC Digitalis se encontram protegidas pelo Código do Direito de Autor e Direitos Conexos e demais legislação aplicável, toda a cópia, parcial ou total, deste documento, nos casos em que é legalmente admitida, deverá conter ou fazer-se acompanhar por este aviso.

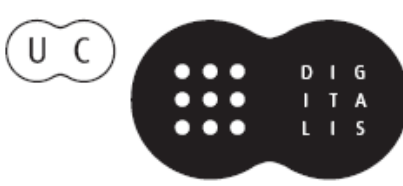


Euro-Atlântico:

Espaço de Diálogos

Isabel Maria Freitas Valente

Iranilson Buriti de Oliveira

(Coord)

\section{VISÕES \\ INTERDISCIPLINARES \\ DA EUROPA \\ E DO MUNDO:}

uma experiência de convergência

disciplinar em homenagem a

Maria Manuela Tavares Ribeiro

Alexandra Aragão

Isabel Maria Freitas Valente

Dulce Lopes

(org.)

Editora da Universidade Federal de Campina Grande

Imprensa da Universidade de Coimbra

2019 


\title{
ESTADOS UNIDOS E EUROPA: ENTRE PARCERIA E ISOLACIONISMO
}

\author{
Miguel de Oliveira Estanqueiro Rocha, PhD \\ Universidade Açores \\ E-mail: miguelrocha25@hotmail.com
}

\begin{abstract}
Resumo
$\mathrm{O}$ isolacionismo norte-americano face à Europa representou uma linha constante da política externa dos Estados Unidos (EUA), desde a sua independência (1776) até ao final do século XIX. Ao invés, no século passado, o envolvimento dos EUA na segurança europeia foi uma realidade incontornável. Tal aliança transatlântica garantiu a paz no continente europeu, para além da derrota dos expansionismos alemão nas duas guerras mundiais e do totalitarismo soviético durante a Guerra Fria. Assim, analisam-se eventos característicos dessa causa, num momento em que presenciamos sinais inquietantes sobre a relevância desta mesma parceria na actual conjuntura internacional.

Palavras-chave: Europa; Integração europeia; Guerra Fria; Relações transatlânticas.
\end{abstract}

\begin{abstract}
American isolationism vis-à-vis Europe represented a constant line of US foreign policy, since its independence (1776) until the end of the nineteenth century. Nevertheless, in the last century, US involvement in European security was an unavoidable reality. Such transatlantic alliance guaranteed peace on the European continent, apart from the defeat of German expansionism in the two world wars and of the Soviet totalitarianism during the Cold War. Therefore, historical events are analysed, at a moment when we are witnessing disturbing signs about the relevance of this same partnership in the current international situation.
\end{abstract}

Keywords: Europe; European integration; Cold War; Transatlantic relations. 
Num momento histórico em que assistimos à ascensão do nacionalismo a nível global - as eleições de Trump e de Bolsonaro são sintomas preocupantes -, em que predomina a suspeita de uma convergência insólita entre o poder de Washington e o do Kremlin, uma experiência governativa inédita entre o populismo de esquerda e o de direita como a italiana, são factos que lançam dúvidas sobre o futuro do projecto europeu e da parceria transatlântica.

Tais sombras existiram noutros períodos históricos, desde a crise do Suez, em 1956, até ao conflito do Iraque em 2003, em que muitos preconizaram o fim desta aliança; contudo, a realidade desmentiu estes cenários pessimistas, reforçando mais os vínculos entre os dois continentes. Por isso, quando debatemos a relevância desta simbiose atlântica no actual contexto internacional, importa reflectir sobre o legado desta aliança singular nas relações internacionais, que garantiu estabilidade no continente europeu.

O isolacionismo americano face aos assuntos europeus é uma linha constante da sua diplomacia, desde a independência até ao final do século XIX. O conflito mantido com a potência colonizadora - a Inglaterra - para a obtenção da sua independência, na qual os revolucionários americanos contaram com o apoio militar francês e espanhol, contribuiu para o natural alheamento da nova nação face aos conflitos existentes no continente europeu. Apesar da aliança com a França, George Washington, o primeiro Presidente da história do país, opôs-se ao envolvimento americano, ao seu lado, contra a Inglaterra em 1795. Esta decisão do Presidente-norte-americano, apoiada por Alexander Hamilton, é considerada uma das mais corajosas da história presidencial do país, que contou com a oposição de Thomas Jefferson e de James Madison, pois estes dois "pais fundadores" não escondiam que o seu coração pendia para o lado francês. (Ketcham, 1990: 337)

Além disso, os problemas mantinham-se nas relações entre os Estados Unidos e a Inglaterra, com tensões entre os dois países, que originaram, mais tarde, a eclosão de um novo conflito militar, entre 1812 e 1815, durante a presidência de James Madison (1809-1817). 
Essa relutância americana às disputas europeias não significava que os Estados Unidos permanecessem indiferentes ao que ocorria no vasto continente americano - uma área fulcral dos seus interesses estratégicos. A proclamação da Doutrina Monroe representou uma advertência aos poderes europeus de que não seriam toleradas ingerências nos destinos do continente americano (Kissinger, 1996: 26).

Outras preocupações consumiam a atenção dos líderes norteamericanos: a extensão do território norte-americano, seja através de aquisições a países europeus - como o caso da Louisiana comprada à França - ou de anexações resultantes de conquistas militares - a Guerra com o México que permitiu o alargamento do território americano. No entanto, outro problema dilacerava a alma estadunidense: a escravatura era a maior chaga moral do país; após décadas de impasse - entre os defensores da abolição da escravatura e os seus opositores - eclodiu uma guerra civil. Esta disputa, que foi seguida com paixão em todo o mundo, nalguns Estados europeus - como a França e a Inglaterra -, não foi vista como nociva, pois a manutenção da divisão entre a União e os rebeldes sulistas poderia favorecer os seus interesses estratégicos e comerciais, sobretudo no algodão (Sá, 2015: 201). A Administração Lincoln chegou mesmo a advertir a Inglaterra de que um reconhecimento britânico da Confederação originaria um conflito militar com os Estados Unidos (Goodwin, 2005: 364). A França, a Inglaterra e a Espanha quiseram aproveitar-se das circunstâncias do conflito americano para poderem intervir militarmente no México. Esta opção acabou por ser rejeitada pela Inglaterra que temia a reacção dos Estados Unidos diante de acto tão hostil (Sá, 2015: 183).

A neutralidade proclamada por esses Estados europeus no conflito procurava também não desagradar às respectivas opiniões públicas, que não escondiam a sua simpatia pela causa da União que Abraham Lincoln liderava. A proclamação da emancipação pelo Presidente Lincoln, em 1863, deu uma nova causa moral à luta do governo federal. Com esta decisão, Lincoln pretendia também influenciar as opiniões públicas europeias, hostis à escravatura, e que se oporiam a qualquer tipo de intervenção dos Estados europeus a favor dos Estados confederados 
(Goodwin, 2005: 468). A posição portuguesa nesta contenda foi de simpatia e de compreensão pela causa de Abraham Lincoln, mantendo os seus portos abertos aos barcos da União (Sá, 2015: 212), atitude que não passou despercebida em Washington e de que Portugal viria a beneficiar no futuro - quando o então Presidente americano Ulysses S. Grant serviu de árbitro entre Portugal e a Inglaterra pela posse da ilha de Bolama, favorável às pretensões portuguesas (Sá, 2015: 220).

As presidências de William Mckinley e, sobretudo, Theodore Roosevelt, são consideradas um ponto de viragem na política externa americana, com os Estados Unidos a assumirem um maior protagonismo no sistema internacional; o Presidente Roosevelt defendia mesmo os benefícios de um papel mais activo dos Estados Unidos no cenário internacional (Kissinger, 1996: 30). A participação americana na Conferência de Berlim sobre Africa, em 1895, e a guerra hispano-americana de 1898 - com a rápida vitória militar americana representaram um sinal de que os poderes dominantes daquela época teriam que contar, no futuro, com os Estados Unidos. O Presidente Roosevelt assumiu o papel de mediador entre a Rússia e o Japão, após a eclosão do conflito entre estes países, que terminou com a vitória nipónica. Os esforços do estadista americano valeram-lhe a atribuição do Prémio Nobel da Paz, em 1906 - o primeiro Nobel atribuído a um Presidente dos Estados Unidos.

As tensões internacionais entre os principais poderes europeus, desde finais do século XIX, originaram o início da I Guerra Mundial (1914-1918). De certo modo, a formação da Tríplice Aliança e da Tríplice Entente - dois blocos europeus antagónicos -era prenúncio de um conflito em grande escala no continente europeu. $\mathrm{O}$ assassinato do arquiduque Francisco em Sarajevo e as posteriores declarações de guerra entre os países europeus mergulharam a Europa numa confrontação bélica.

Os Estados Unidos proclamaram então a sua neutralidade e o Presidente Wilson mostrava-se avesso a interferir nos assuntos europeus. Todavia, as constantes provocações alemãs (com os ataques de submarinos alemães contra barcos americanos, provocando centena de 
mortos) e um suposto incitamento germânico ao México para declarar guerra aos Estados Unidos, não deixaram outra alternativa a Wilson, senão solicitar ao Congresso americano autorização para declarar guerra à Alemanha (Ferrel, 1998: 133-134). A entrada americana na I Guerra Mundial foi um ponto de viragem a favor dos aliados, tendo o conflito terminado em 1918, após a chegada das tropas americanas ao continente europeu. As provocações alemãs aos Estados Unidos foram um erro com consequências trágicas para Berlim, pois a retirada da Rússia do conflito enfraquecia os aliados e concedia uma vantagem à Alemanha, mas a posterior chegada das tropas americanas e do respectivo material bélico foi um "bálsamo" para as tropas aliadas, cansadas de anos exaustivos de combate nas trincheiras.

A intervenção americana não pretendia apenas derrotar a Alemanha, mas sim influenciar uma nova ordem internacional que se seguiria à derrota germânica e à convocação de uma Conferência de paz. O Presidente Woodrow Wilson expôs a sua visão sobre a nova ordem pós-conflito no Congresso americano - o famoso discurso dos Catorze Pontos: este plano audacioso, revolucionário e idealista, rompia com a prática diplomática europeia de equilíbrio de poder e da 'realpolitik'. Wilson explicou às opiniões públicas europeias durante a sua 'tournée' europeia (1918) a sua visão para a nova ordem internacional (Kissinger, 1996:195). O Presidente sugeriu a criação de um fórum internacional, a Sociedade das Nações (Kissinger, 1996: 194) que reunisse os Estados e onde se discutissem e debatessem os assuntos relevantes da política internacional. Algumas propostas americanas desagradavam aos principais países europeus, como a da defesa do conceito de autodeterminação, que as capitais europeias entendiam como um ataque de Washington às suas possessões coloniais (Kissinger, 1996: 191). Na conferência de Versalhes predominava o desejo de responsabilizar a Alemanha pelos custos do conflito, sendo impostas condições humilhantes a Berlim, não obstante os intentos de Wilson em contrariá-las. No âmbito da política interna norte-americana, o Senado americano vetou a adesão do país à recém-criada Sociedade das Nações, desferindo um golpe fatal no seu projecto político. Os Estados 
Unidos voltaram a privilegiar o isolacionismo na sua política externa em relação à Europa.

O período entre as duas guerras foi marcado pela turbulência financeira e política e pela emergência de regimes nacionalistas e fascistas no continente europeu. $\mathrm{O}$ receio da propagação do marxismoleninismo soviético na Europa e os efeitos da crise financeira de 1929 favoreceram a ascensão dos movimentos nacionalistas, como o de Hitler na Alemanha e o de Mussolini na Itália. A política do rearmamento alemão e as acções provocatórias e expansionistas dos governos de Berlim e Roma depararam-se com vagos protestos franco-britânicos, decorrentes do pacifismo das suas opiniões públicas. A Guerra Civil espanhola entre os republicanos e os nacionalistas representou o último "prego no caixão" precário da paz, com a intervenção alemã, italiana, e também portuguesa, em favor do movimento nacionalista de Franco, enquanto os republicanos apenas puderam contar com a União Soviética e as brigadas de voluntários internacionais que vieram em seu socorro.

A década de trinta representou um ponto de viragem na história norte-americana: a incapacidade da administração republicana de Herbert Hoover (1929-1933) em lidar com as consequências da crise financeira, levou à sua derrota nas eleições presidenciais de 1932 e à eleição de Franklin D. Roosevelt como o $32^{\circ}$ presidente da história federal do país. O período de governação de Franklin Roosevelt (19331945) originou profundas transformações na sociedade americana com a aplicação do programa "New Deal", que recuperou o país da crise e criou alicerces sólidos para um novo ciclo de prosperidade económica, com um papel relevante do Estado; o mesmo também se passou no âmbito das relações internacionais: a administração Roosevelt rompeu com a prática isolacionista da diplomacia americana, convencendo o país a participar do esforço militar que se tornaria fundamental para a derrota do nazismo e do fascismo na II Guerra Mundial (Kissinger, 1996: 321). A proclamação da neutralidade americana, após a eclosão do segundo grande conflito em 1939, não impedia o Presidente Roosevelt de manifestar a sua simpatia pela causa das democracias, que vigoravam 
no Reino Unido e na França. No entanto, o Presidente tinha que lidar com uma opinião pública contrária a esse envolvimento, o que obrigou Roosevelt a uma gestão política habilidosa. O ataque japonês a Pearl Harbour (7 de Dezembro de 1941) e a declaração posterior de guerra da Alemanha aos Estados Unidos facilitou a tarefa de Roosevelt, que assim pôde alargar o esforço de guerra americano ao teatro europeu. A entrada dos Estados Unidos e da União Soviética a favor dos aliados conduziu à derrota dos partidários do Eixo, em 1945.

Após a vitória dos aliados em 1945, os americanos depararam-se com a seguinte dilema: qual deveria ser o papel dos Estados Unidos na nova ordem internacional? Voltar à prática do isolacionismo que não resultara, ou assumir o seu estatuto de potência mundial e envolver-se nos assuntos europeus? Franklin D. Roosevelt não teve a possibilidade de se debruçar sobre este dilema, porque faleceu a 2 de Abril de 1945, sendo substituído na presidência por Harry Truman. Truman desconfiava das pretensões da União Soviética no período pós-conflito e considerou ser dever histórico dos Estados Unidos opor-se aos desígnios expansionistas do Kremlin. As intenções de Roosevelt de um mundo liderado por quatro poderes - Estados Unidos, União Soviética, Reino Unido e China - (Kissinger, 1996: 345), dava lugar à confrontação entre Washington e Moscovo. A presidência de Truman (1945-1953) é uma das mais marcantes a nível da política externa americana: as opções diplomáticas tomadas pela sua Administração tiveram impacto na política externa americana e nas administrações seguintes, fossem elas democratas ou republicanas (Kissinger, 1996: 370).

Entretanto, uma Europa destroçada representava uma oportunidade única para os partidos comunistas europeus, alinhados com Estaline, ascenderem ao poder ou ganharem grande influência na governação de países importantes como a França e a Itália. Consciente de que a pobreza e a ruína apenas favoreciam os comunistas, os americanos propuseram um plano de recuperação económica para salvar a Europa do caos e da pobreza, designado de Plano Marshall (Mccllough, 1992: 563); este programa também foi oferecido aos países de Leste e à própria União Soviética, que o recusaram. O plano Marshall permitiu 
uma recuperação económica da Europa ocidental, com o declínio da pobreza e a ascensão de uma classe média avessa a radicalismos políticos e económicos. O capitalismo com rosto social demonstrava ser capaz de proporcionar um período de prosperidade económica na Europa.

A tomada do poder de partidos alinhados com Moscovo, na Europa do Leste, alertou os países europeus para a necessidade de uma maior cooperação entre eles face uma ameaça, cada vez mais real, da União Soviética. Todavia, uma aliança só com os países europeus poderia não ser suficiente para dissuadir Estaline de qualquer acção hostil. $O$ poderio militar americano - a única potência nuclear mundial até à década de cinquenta, após a utilização da arma atómica contra o Japão em 1945 - seria o único elemento que demoveria a União Soviética de qualquer acção hostil. O discurso de Churchill em Foulton, em 1946, alertando para a nova realidade do perigo soviético, e a decisão do Presidente Truman em apoiar a Grécia e a Turquia (McCullough, 1992: 540-541), simbolizaram a determinação ocidental em resistir à União Soviética.

A aprovação da resolução Vandenburg no Congresso americano, em 1948, autorizou o Presidente Truman a participar numa aliança militar com países europeus. Assim, a 4 de Abril de 1949, foi assinada na cidade de Washington um tratado militar defensivo, que incluía os Estados Unidos, Canadá, França, Reino Unido, Holanda, Bélgica, Luxemburgo, Itália, Dinamarca, Noruega e a Islândia, simbolizando esta aliança uma ruptura com a tradição histórica norte-americana. O Presidente Truman reconheceu, mais tarde, que a criação da NATO e o Plano Marshall eram os maiores legados históricos da sua presidência (McCullough, 1992: 735). Depois da sua constituição em 1949, a Grécia, a Turquia e a RFA aderiram à NATO, cuja sede inicial foi em Paris, até à sua transferência para Bruxelas, em 1967 - como consequência da retirada da França da estrutura militar da NATO e o pedido gaulês para que fossem encerradas as bases americanas e da aliança em solo nacional.

A divisão da Alemanha em duas zonas de influência, uma ocidental e outra comunista, representou um dos aspectos mais dramáticos da 
Guerra Fria. A criação da República Federal da Alemanha, próxima dos países ocidentais, e da República Democrática da Alemanha, próxima do bloco comunista, alterou o quadro de estabilidade europeia. A consolidação da democracia na RFA e a integração do país nas organizações internacionais eram um objectivo fulcral da diplomacia americana; para isso ocorrer, tornava-se necessário ultrapassar o antagonismo franco-alemão, sem o qual não haveria paz na Europa. A proposta de uma Comunidade Europeia do Carvão e do Aço (CECA), em 1950, pelo Ministro francês dos Negócios Estrangeiros, Robert Schuman, originou o projecto mais inovador da história da humanidade, de uma maior integração entre os países europeus. A assinatura da CECA e o sucesso do projecto proporcionou depois que os países participantes França, RFA, Itália, Holanda, Bélgica e Luxemburgo - concordassem em aprofundar essa cooperação e assinassem o Tratado de Roma, em 1957, que instituiu a Comunidade Económica Europeia (CEE). Os Estados Unidos apoiaram este projecto entusiasticamente; contudo, países como o Reino Unido decidiram criar outra organização europeia, menos ambiciosa e apenas de comércio livre, em 1960, designada de EFTA.

O fim dos impérios coloniais ocorreu na sequência do término do segundo grande conflito. Não se podia continuar a negar aos povos africanos e asiáticos a aplicação do princípio de autodeterminação e da independência. Ora, estes continentes foram outro palco de batalha entre as duas superpotências, Estados Unidos e a União Soviética. A descolonização representou um dilema para a diplomacia americana: por um lado, a sua tradição anticolonial e a sua memória histórica - os Estados Unidos foram o primeiro país a libertar-se do domínio colonial - colocavam Washington entre os defensores da autodeterminação e a independência dos povos, nem que fosse para competir com Moscovo; por outro lado, também deviam solidariedade aos seus aliados europeus que seriam as principais "vítimas" do término dos impérios coloniais. Ficaram para a história os desentendimentos de Washington com a Holanda por causa da independência da Indonésia, assim como os atritos entre os Estados Unidos e Portugal, mormente quando o regime ditatorial português se recusou a aplicar o princípio 
de autodeterminação em Angola e Moçambique.

A crise do Suez foi um ponto marcante nas relações transatlânticas: o Presidente Nasser nacionalizou o canal do Suez, em 1956, enfurecendo Paris e Londres, que foram afectados por esta decisão do presidente egípcio; então, a França, o Reino Unido e Israel lançaram um ataque militar contra o Egipto; no entanto, esta operação militar chocou os países africanos, e também Moscovo, que ameaçou os protagonistas envolvidos com consequências terríveis; também Washington desaprovou esta acção, considerando-a mais própria de um colonialismo em desuso e obrigando os seus aliados europeus a terminarem com os ataques. A oposição americana marcou as relações entre estes três protagonistas mais importantes das relações transatlânticas: enquanto Paris concluiu que deveria emancipar-se face aos Estados Unidos e iniciar o seu programa atómico, o Reino Unido preferiu encostar-se às posições da diplomacia americana, pensando ter assim um maior influência nas opções da potência militar do mundo (Kissinger, 1996: 476). A IV República francesa tomou a decisão histórica de iniciar o seu programa atómico (Roussel, 2003:179), mas foi o prestígio de De Gaulle, fundador da V República, que conseguiu dotar o seu país do arsenal nuclear e de resistir às opções internas e externas que se opunham a esta pretensão francesa.

A década de sessenta foi quer um período de crises nas relações transatlânticas quer de propostas inovadoras para o futuro das mesmas. A ascensão de John Kennedy à Casa Branca foi seguida com expectava na Europa: o catolicismo do jovem Presidente americano tinha eco no Velho continente, com uma visão mais inovadora sobre o papel que os Estados Unidos deveriam desempenhar no projecto de integração europeia: de facto, Kennedy defendia o reforço do compromisso da NATO, o estabelecimento de uma nova parceria entre os dois continentes, uma parceria atlântica (Schelsinger, 2002: 299) que não se centrasse unicamente na agenda da Guerra Fria. Entusiasta da integração europeia, o Presidente mantinha contactos com Jean Monnet e o movimento federalista, seguindo com atenção os debates que decorriam na Europa. A adesão do Reino Unido à CEE era apoiada por 
Washington, que esperava que se concretizasse durante essa década. No entanto, o projecto do Presidente chocava com a intransigência do Presidente francês De Gaulle: em Janeiro de 1963, vetou a adesão britânica, pois, para este grande estadista francês, a adesão britânica significaria transpor para a CEE a influência americana no continente; esta decisão francesa chocou os seus parceiros comunitários que defendiam a adesão britânica. $O$ veto francês só foi levantado pelo sucessor de De Gaulle, o Presidente Georges Pompidou, permitindo a adesão do Reino Unido à Comunidade Europeia em 1973.

Apesar destas divergências entre Washington e Paris, que se agravariam ainda mais durante essa década, Paris demonstrou a sua solidariedade transatlântica nas crises do Berlim, em 1961, e da Crise dos Mísseis de Cuba, em 1962 - as crises mais graves do período da Guerra Fria. A retirada francesa da estrutura militar da NATO foi o culminar das tensões franco-americanas durante a década de sessenta. A reacção americana de indignação inicial evoluiu depois para um maior pragmatismo (Kaplan, 1998: 117), pois, apesar da retórica nacionalista do Presidente francês, o país permanecia no Tratado de Atlântico Norte e a idade avançada do então Presidente antevia a sua sucessão. As relações bilaterais entre os dois países, após de uma década tensa, melhorariam nos anos seguintes.

A década de setenta foi a da consolidação da 'détente' entre os blocos ocidental e comunista, iniciada na década anterior, com acordos entre os Estados Unidos e a União Soviética na corrida aos armamentos, verificando-se também uma progressão nas relações entre as duas Alemanha, com o reconhecimento mútuo e acordos sobre Berlim. A assinatura da Acta da Helsínquia, em 1975, entre todos os Estados europeus foi o culminar do processo de 'détente' entre os dois blocos. A democratização de Portugal e de Espanha, após décadas de autoritarismo nos dois países ibéricos, e da Grécia, após o regime dos Coronéis, é outro dado fundamental na história europeia: a democratização dos Estados do Sul da Europa, membros da Aliança Atlântica - a Espanha aderiu em 1981 - permitiu-lhes, posteriormente, aderir à Comunidade Europeia. 
Contudo, o final da década de setenta e de oitenta marcou o regresso à confrontação dos dois blocos, com muitos a temerem o regresso aos períodos tensos do início da Guerra Fria e da década de sessenta. Apesar dos medos de uma eclosão de um conflito entre os dois blocos, dada a retórica agressiva existente entre Washington e Moscovo, o final da década acabou por proporcionar a desintegração surpreendente do bloco comunista e o fim da Guerra Fria. A ascensão de Mikael Gorbachev, a sua política de abertura da sociedade soviética e ao mundo -Glasgnot e Perestroika - e a melhoria nas relações com os Estados Unidos, durante a administração de Ronald Reagan, reduziu as tensões internacionais, culminando esta década vertiginosa com a desintegração do bloco comunista na Europa de Leste e o fim da Guerra Fria, portanto do mundo bipolar que vigorava desde 1945.

A queda do Muro de Berlim em 1989 representou o fim de uma era na Europa, permitindo a reunificação da Alemanha. Uma Alemanha reunificada levantava alguns receios, dado o histórico passado trágico. Por isso, não espantou que, numa fase inicial, a França e o Reino Unido se tenham mostrado pouco entusiastas desta unificação, evoluindo, posteriormente, para um apoio. A unificação alemã reforçou o empenhamento do país no projecto europeu e o eixo franco-alemão continuou a ser o motor da integração europeia, com as lideranças de François Mitterrand e Helmut Kohl. A assinatura do Tratado de Maastricht representou um passo inovador no sentido de uma maior unidade política entre os europeus.

A desintegração do bloco comunista e o fim da Guerra Fria não implicou o término do vínculo transatlântico e da NATO. Durante a década de noventa, procedeu-se à revisão do conceito estratégico da organização, por duas vezes (1991 e 1999), deixando esta de ser uma organização puramente defensiva e podendo intervir em zonas geográficas fora da sua zona de intervenção. A capacidade militar da Organização do Tratado de Atlântico Norte seria utilizada na Bósnia e no Kosovo; além disso, assistimos ao alargamento da Aliança Atlântica aos antigos membros do Pacto de Varsóvia. A União Europeia também passou por dois alargamentos aos países do antigo bloco comunista. 
A década de noventa, considerada transitória nas relações internacionais, foi o período em que os Estados Unidos assumiram a responsabilidade de gestão do sistema internacional: o vínculo transatlântico reforçou-se, os aliados europeus - destacando-se o Reino Unido e a França - intervieram militarmente ao lado do seu aliado histórico na Guerra do Golfo, em 1991, e nos conflitos da Bósnia e do Kosovo. A década de noventa caracterizou-se ainda pela emergência de um novo tipo de terrorismo, o fundamentalismo islâmico, em que os Estados lidam, pela primeira vez, com ameaças de actores não estatais. A simbiose atlântica também se evidenciou nestes domínios e também numa visão idênticas dos novos perigos que pairam sobre o sistema internacional, desde as alterações climáticas até às doenças infectocontagiosas.

De certo modo, os ataques terroristas perpetrados contra os Estados Unidos, em 11 de Setembro de 2001, colocaram um fim nesse período transitório das relações internacionais. Atacados no seu próprio solo por um grupo terrorista, lidando com uma ameaça não estatal, que não podia ser combatida, unicamente, nos moldes tradicionais, os Estados Unidos procederam a uma ampla revisão do seu conceito estratégico, com a apologia do princípio do ataque preventivo - uma decisão perigosa no âmbito do direito internacional. A aliança transatlântica actuou em coordenação no ataque americano ao Afeganistão, mas o mesmo não se passou no Iraque, onde os aliados europeus se dividiram entre o apoio e a crítica à invasão americana do Iraque em 2003, destacando-se a França e a Alemanha na oposição aos ataques militares unilaterais decretados pela Administração Bush (Chirac, 2011: 364-365).

A crise transatlântica de 2002 colocou em dúvidas a validade desta pareceria, tendo mutos analistas previsto o fim da mesma. Neste âmbito, destacou-se Robert Kagan, que, no seu livro O Paraíso e o Poder: a América e a Europa na nova ordem mundial, prognosticou o fim deste vínculo, devido às visões irreconciliáveis entre os dois continentes sobre a gestão do sistema internacional, em que a Europa era Vénus e a América Marte. Por seu turno, Timothy Garton Ash discordou desta visão, preconizando o reforço desta aliança, apelando a uma nova 
agenda atlântica para o século XXI (Ash, 2005: 221). Contrariando as visões mais pessimistas, não ocorreu nenhuma ruptura entre a Europa e os Estados Unidos, que aproximaram as suas posições, após o grande choque de 2003.

A administração Obama (2001-2009) prometeu o regresso da América à sua tradição multilateral, rompendo com a prática da presidência de George W. Bush (2001-2009), em que o unilateralismo predominara nas opções da política externa americana, sobretudo durante o seu primeiro mandato (no segundo verificou-se uma aproximação à Europa). A ascensão de Obama despertou grande expectativa na Europa, como comprovou a recepção entusiasta ao então candidato democrata, saudado por centenas de milhares de alemães, em Berlim (2008), ao então candidato democrata. A eleição de Obama fora seguida com euforia, porque a sua retórica de campanha e o seu estilo de governação prometiam uma governação que seria a antítese do seu predecessor e que contribuíra para o decréscimo do prestígio americano na Europa.

Poderá ser ainda prematuro fazer um juízo mais aprofundado da sua política externa americana, dos seus sucessos e fracassos, durante os oito anos de governação de Obama. A atribuição do Prémio Nobel ao Presidente em 2009 embaraçou a própria administração e surpreendeu o mundo por esta se basear mais na promessa que o presidente representava e nos compromissos assumidos para a política externa, do que em feitos e legados que, normalmente, justificam a atribuição deste prémio prestigiado (Chat, 2017:141). Relativamente às relações com a Europa, saliento dois momentos: a intervenção militar norteamericana, com os seus aliados franceses e britânicos, na Líbia, apesar de vozes contrárias na administração Obama - como o Secretário de Defesa, Robert Gates que se opunha a um novo conflito contra um país muçulmano, por considerar que não ameaçava os interesses estratégicos americanos (Landler, 2016: 168-169). O Presidente Obama aprovou a participação americana, cedendo, no entanto, a primazia das operações militares aos seus aliados europeus (Cholet, 2016: 99-100); a invasão da Crimeia pela Rússia foi outro evento marcante, com os americanos e os aliados europeus - que não estabeleceram uma estratégia coerente 
para lidar com esta crise -, a terem que enviar aviões de combate, material militar e tropas para os países da NATO próximos de Moscovo, como uma espécie de aviso a Moscovo para a não provocar (Cholet, 2016:166). Este reforço do compromisso americano surgiu num momento em que muitos consideravam que os Estados Unidos estavam a virar-se para o Pacífico a nível estratégico; apesar das divergências com Angela Merkel sobre as políticas económicas adequadas para lidar com a crise financeira de 2007-2008, a Chanceler alemã tornou-se na interlocutora europeia do Presidente americano. Obama interveio ainda na crise da dívida da Grécia (2015), actuando como mediador, de modo a evitar medidas retaliatórias contra Atenas, que poderiam colocar em causa o seu alinhamento tradicional com o bloco ocidental e participou activamente na campanha do Brexit, como defensor da permanência britânica na União Europeia.

Por isso, quando debatemos o futuro desta simbiose atlântica, não é de excluir uma ruptura no futuro, devendo a Europa prosseguir com os seus esforços em dotar-se de maior autonomia face ao seu aliado histórico norte-americano. Todavia, quando reflectimos sobre o seu legado histórico, quando homenageamos os mortos do combate nas duas guerras mundiais nas efemérides comemorativas dos conflitos, constatamos que esta Aliança não perdeu a sua validade histórica no actual contexto internacional, e que a Europa e a América do Norte ainda precisam um do outro, e que, independentemente das divergências que existem e sempre existirão, esta parceria ainda é a melhor garantia de segurança num mundo cada vez mais conturbado.

\section{Bibliografia}

ASH, Timothy Garton, Free World, why a crisis of the West reveals the opportunity of our time. London: Penguin Books, 2005.

BOZO, Frédéric De Gaulle, the United States and the Atlantic Alliance: two strategies for Europe. Oxford: Rowman \& Littlefield Publisher, 2001.

COSTIGLIOLA, Frank, France and the United States: the Cold Alliance since World War II. New York: Macmillan Publishing Company, 1992. 
CHAIT, Jonathan, Audacity, how Obama defied his critics and created a legacy that will prevail. New York: Harper Collins, 2017.

CHIRAC, Jacques, Mémoires: chaque pas doit être un but. Paris: Nil Éditions, 2009.

CHIRAC, Jacques, Mémoires: le temps présidentiel. Paris: Nil éditions, 2011.

CHOLET, Derek, The Long Game, how Obama defied Washington and redefined America's Role in The World. New York: Public Affairs, 2016.

DALLEK, Robert, John F. Kennedy: an Unfinished Life 1917-1963. Penguin Books: London, 2003.

, Camelot's Court, Inside the Kennedy White House. Harper Collins Publishers: New York, 2013.

LANDLER, Mark, Alter Egos, Hillary Clinton, Barack Obama, and the Twilight Struggle over American Power. London: WH Allen, 2016.

FERREL, Robert H., American Diplomacy: the Twenty Century. New York-London: W.W. Norton \& Company, 1988.

FUKUYAMA, Francis, "The End of History?" The National Interest, (16) Summer1989, 1989.

FUKUYAMA, Francis, The End of History and the Last Man. London: Hamish Hamilton, 1992.

GAULLE, Charles de, Memórias de Esperança: a Renovação 19581962. Lisboa: Publicações Europa-América, 1970.

GERWARTH, Robert \& Erez Manela (org), Impérios em Guerra 1911-1923. D. Quixote: Lisboa, 2014.

GOODWIN, Doris Kearns, Team of Rivals: the Political Genius of Abraham Lincoln. New York: Penguin Books, 2005.

KAGAN, Robert, O Paraíso e o Poder: a América e a Europa na nova ordem mundial. Lisboa: Gradiva, 2003.

KAPLAN, Lawrence S., NATO and the United States: the enduring alliance. Boston: Kent State University, 1988.

KETCHAM, Ralph, James Madison: a biography. Charlottesville and London: Virginia University Press, 1990.

KISSINGER, Henry, A Diplomacia, trad. port. Lisboa: Gradiva (1996), 1994. 
MAHONEY, Richard, JFK: Ordeal in Africa.

Oxford University Press: Oxford, New York, 1983.

MCCUlLOLOUGH, David, Truman. New York: Simon \& Schuster Paperbacks, 1992.

MONNET, Jean, Mémoires. Paris: Fayerd, 1976.

ROUSSEL, Éric, De Gaulle, 2 vols., Lisboa: Verbo, 2003.

SÁ, Tiago Moreira de, História das Relações Portugal-EUA (17762015). Lisboa: Dom Quixote, 2015.

SCHELSINGER, Artur M., A Thousand Days: John F. Kennedy in the White House. London: Andre Deutsch, 1965.

SCHELSINGER, Artur M., Robert Kennedy and his Times. London: Andre Deutsch, 1978.

SORENSEN, Thed, Kennedy. Lisboa: Aster, 1966.

STONE, Oliver \& Peter Kuznick, The Untold History of the United States. Ebury Press: London, 2013. 